\title{
Differential effects of pay-it-forward and direct-reciprocity on prosocial behavior
}

By: Zhiyong Yang, Narayan Janakiraman, Mehdi T. Hossain, and Douglas B. Grisaffe

Yang, Zhiyong, Narayan Janakiraman, Mehdi T. Hossain, and Douglas B. Grisaffe (2020), "Differential Effects of Pay-It-Forward and Direct-Reciprocity on Prosocial Behavior," Journal of Business Research, 121, 400-408. https://doi.org/10.1016/j.jbusres.2018.11.050

\section{cc) (†) $\ominus$}

This work is licensed under a Creative Commons Attribution-NonCommercialNoDerivatives 4.0 International License.

Abstract:

This research conceptualizes the distinction between pay-it-forward and direct-reciprocity tendency from a construal level perspective, and examines such differences in three studies. Study 1 develops Pay-It-Forward Tendency scale and validates it in both the U.S. and India. Study 2 uses the scale to gather data from software engineers in both the U.S. and India, showing that Indian software professionals have a lower pay-it-forward (vs. direct-reciprocity) tendency, which in turn leads to more pay-it-forward behavior, whereas American software professionals have similar levels of pay-it-forward and direct-reciprocity tendency. Consistent with the construal level account, Study 3 shows that individuals high (vs. low) in direct-reciprocity have lower preferences for charitable causes with delayed (vs. immediate) impact, whereas those high and low in pay-it-forward show equal preferences for these causes. Similarly, donation intentionbehavior consistency is positively related to pay-it-forward, but negatively associated with direct-reciprocity. Theoretical contributions and managerial implications of these findings are discussed.

Keywords: pay-it-forward | direct-reciprocity | scale development | construal level | crosscultural

\section{Article:}

\section{Introduction}

Pay-it-forward (PIF) is a growing field, examining individual decisions to reciprocate acts of kindness to strangers when individuals themselves are the beneficiary of someone else's acts of kindness. This is different from direct reciprocity (DR), where individuals reciprocate acts back to the giver. As an example of PIF, during Christmas 2012 at a Tim Hortons in Winnipeg, Canada, one person paid for the next customer-in-line's coffee. The next person, in turn, reciprocated to the following person, and the trend continued for about $3 \mathrm{~h}$, with 228 consecutive orders filled on someone else's tab (Taylor, 2012). Other fairly well-known PIF behaviors include restaurant drive-ins, anonymous blood donations, and helping a stranded motorist.

Notably, PIF is not limited to physical locations and is prevalent in the high-tech software industry (Suri \& Watts, 2011). In online communities, voluntary contributions are pervasive: 
every day, thousands of people share information and provide codes to improve open source software in pay-it-forward chains in the virtual space (Kang, Kim, Woo, Park, \& Kim, 2015). These are modeled as social contagion within the open source software community (Tsvetkova \& Macy, 2014). Anecdotal evidence suggests that the success of Silicon Valley stems from various individuals dedicating their time and knowledge to helping unknown others, ${ }^{1}$ and software billionaires in India wish to create a culture of pay-it-forward behavior in that country, in order to facilitate a Silicon Valley there. ${ }^{2}$

Previous research on PIF has mainly focused on the driving factors that motivate people to engage in pay-it-forward behavior (Barta, McNamara, Huszár, \& Taborsky, 2011; Rankin \& Taborsky, 2009), as well as the extent to which an individual reciprocates positive acts of kindness versus negative acts of selfishness (Gray, Ward, \& Norton, 2014). These studies provide intriguing findings. However, we know little about the underlying differences between PIF and DR. On one hand, PIF and DR are common in the nature of reciprocity, i.e., both capture the likelihood of passing a similar act of kindness onto another person. On the other hand, a key difference is that PIF usually happens between unknown individuals, or with distant others, whereas direct reciprocity happens between individuals who have interacted with each other, i.e., between close others (Buchan, Croson, \& Dawes, 2002).

Extant research on how construal level affects moral judgements and altruistic decisions has shown that contextual variables related to the level at which individuals mentally construe events (e.g., social distance, and temporal distance) are likely to impact how they make downstream moral judgements (Eyal, Liberman, \& Trope, 2008). High-level construal or a more abstract mindset has been shown to make individuals discriminate less between close and distant others, since inducing high-level construal involves applying moral principles to judge others' actions that are fairly stable across social distances (Fujita, Eyal, Chaiken, Trope, \& Liberman, 2008). In contrast, inducing low-level construal makes individuals susceptible to salience of situation-specific considerations and whether resulting in reciprocity is with a known individual or an unknown person. Considering these construal level arguments, we suggest that pay-itforward tendency and direct-reciprocity tendency are two divergent constructs, and will be differentially responsive to variables related to the level at which mental construals are constructed. In particular, proclivity to pay-it-forward is associated with high-level construal, whereas proclivity to direct-reciprocity is associated with low-level construal.

As a first step in this research, we develop and validate a construct that measures individual level PIF and show that PIF is distinctly different from the existing construct DR (Perugini, Gallucci, Presaghi, \& Ercolani, 2003). We further show that PIF proclivity better predicts PIF behavior than DR. In this regard, we look at how software professionals improving an open source software make decisions to post either to a public repository (a PIF decision) or to a private repository (a DR decision), as these decisions affect who would benefit with access to the new code being posted on GITHUB, which is the biggest software forge used by software professionals to share code improvements with others.

\footnotetext{
${ }^{1}$ https://www.forbes.com/sites/kevinready/2012/08/23/paying-it-forward-silicon-valleys-open-secret-tosuccess/\#19303c532ec3

${ }^{2}$ https://economictimes.indiatimes.com/small-biz/startups/newsbuzz/india-needs-to-cultivate-pay-forward-culturejyoti-bansal/articleshow/63133539.cms
} 
Further, we examine three variables that are closely related to the construal level at which individuals make decisions, namely individuals' individualism/collectivism orientation, charitable cause type, and donation intention-behavior consistency. Paying kindness forward follows the fundamental philosophy of reciprocity, i.e., "Help anyone, if helped by someone" (Rankin \& Taborsky, 2009). This principle is widely accepted not just by individualistic countries (e.g., the U.S., Canada), but also by collectivistic countries (e.g., India, China). However, the degree of forwarding the kindness to others is likely to be affected by individuals' cultural orientation to individualism or collectivism. Previous research shows that individuals from individualistic countries ("individualists") construe events at a much higher construal level than individuals from collectivistic countries ("collectivists"; Lee, Aaker, \& Gardner, 2000). As a result, individualists are less sensitive to in-group and out-group membership differences; in contrast, collectivists show a marked preference for in-group members over out-group members (Balliet, Wu, \& De Dreu, 2014; Yang, 2008). Given that PIF is usually related to an out-group member (i.e., an unknown person) and DR is often associated with an in-group member (i.e., a close other), difference in construal levels across individualists and collectivists sets up a natural platform for us to examine the conceptual distinction between PIF and DR.

Understanding the conceptual differences between PIF and DR has significant implications to pro-social behavior in general and donation in particular. In this research, we focus on two important issues in donation: (1) how donors form their donation portfolio, and (2) why some people have greater intention-behavior consistency than others. Donation from individual contributors is made up of the biggest portion, much higher than from companies (Giving USA, 2013). To attract donors, charitable organizations (e.g., GlobalGiving) provide a myriad of projects for potential donors to choose from. One difference among these charitable causes is immediacy of the outcome, with some causes (e.g., poverty) being perceived to have immediate impact by donors, other causes (e.g., ozone layer depletion) being perceived to have more delayed impact (Hossain \& Yang, 2014). In this research, we examine how PIF and DR tendency differentially affect individuals' preference for one type of causes over the other, as the immediacy of cause outcome is closely related to construal level. Related to above, donation intention-behavior consistency is another important topic that is largely neglected by previous researchers. Donation intention reflects individuals' pre-commitment to be executed later. We believe that, in the context of donations, the concrete thinking induced by low construal level decreases intention-behavior consistency and increases focus on immediacy of impact. Consequently, PIF and DR tendency should have differential effects on individuals' donation intention-behavior consistency.

Findings from this research are important to both researchers and marketing practitioners. From a theoretical perspective, our research contributes to the reciprocity literature by developing a chronic measure of PIF tendency. Further, this research represents the first to suggest construal level as a key process that underlies the distinction between PIF and DR. Finally, building upon the construal level account, we identify three theoretical factors that set up contingencies for paying forward behavior, including individuals' individualism-collectivism orientation, charitable cause outcome, and donation intention-behavior consistency. From a managerial perspective, our findings can help managers and social workers develop better programs to induce pro-social behavior in both the physical world and the virtual domain. For example, 
managers of IT firms can find ways and means (e.g., ad appeals highlighting immediacy of impact) to increase participation in open source software development across different countries.

In the sections that follow, we start by providing conceptual background on the commonalities and differences between PIF and DR, and then theorize on how construal level can explain such differences. In the next section, we develop hypotheses on the three theoretical factors that are closely related to construal level. Afterwards, we report results of three empirical studies. Study 1 develops a reliable PIF tendency scale and validates it in both the U.S. and India. Study 2 uses the scale developed in Study 1 to gather data from software engineers in both the U.S. and India, showing that Indian software professionals have a lower tendency to engage in PIF than to engage in DR, which in turn leads to more PIF behavior (posting relatively more to public vs. private repositories), whereas American software professionals have similar levels of tendency to engage in pay-it-forward and direct-reciprocity (posting similarly to both public and private repositories). Consistent with our construal level account, Study 3 shows that individuals high (vs. low) in DR have lower preferences for the charitable causes with delayed (vs. immediate) impact, whereas those high and low in PIF show equal preferences for these charitable causes. In a similar vein, donation intention-behavior consistency is positively related to PIF, but negatively associated with DR.

\section{Theoretical background}

\subsection{Pay-it-forward and direct-reciprocity}

Pay-it-forward and direct-reciprocity are both reciprocal behaviors undertaken to benefit other people. Direct-reciprocity drives an individual "B" who has been helped by an individual "A," to give back to "A." PIF is characterized by an individual $\mathrm{B}$ who is the recipient of A's generosity to reciprocate to an unknown individual $\mathrm{C}(\mathrm{A} \rightarrow \mathrm{B} \rightarrow \mathrm{C})$, rather than to the same individual $\mathrm{A}$ $(\mathrm{A} \rightarrow \mathrm{B} \rightarrow \mathrm{A})$. Relative to direct-reciprocity, where receiving from and giving to is the same person, pay-it-forward is often one-shot anonymous dealings with strangers (Gray et al., 2014). Various factors such as need for equitable distributions, salience of partner identity, and the effect on one's own reputational status can potentially affect the type and level of reciprocity individuals engage in (Jung, Nelson, Gneezy, \& Gneezy, 2014).

A commonality between PIF and DR is that they belong to the prosocial behavior family (Grant $\&$ Dutton, 2012). The norm of reciprocation - the rule that obligates people to repay favors - is one of the most prevalent social norms (Gouldner, 1960). It helps society build trust among individuals due to a focus on equity in relationships (Kelln \& Ellard, 1999). The rule is so deeply ingrained in most individuals via socialization that these people have been shown to reciprocate help to complete strangers, even when interactions between them and the beneficiary is only one time and there is no economic benefit to the giver (Jung et al., 2014). When individuals interact repeatedly, direct-reciprocity often governs their behavior (Bahr \& Requate, 2014). Another commonality is that both PIF and DR are conditional generosity behaviors induced by feelings of obligations, as individuals reciprocate because they feel obligated to give back (Cialdini \& Goldstein, 2004). 
Despite these common traits, PIF and DR also have noticeable differences. In general, PIF is less common than DR (Nowak \& Roch, 2007). This is mainly due to high degrees of "conformation to the norms of fairness" and "concern for self" associated with PIF and DR, respectively (Jung et al., 2014). In the situation of direct-reciprocity, strategic and far-sighted self-interest is obvious (Diekmann, 2004). Direct-reciprocity can strengthen the relationships among family members and friends, and reduce transaction costs in social exchanges with others (Whiteley, 2000). Different from direct-reciprocity, pay-it-forward goes less by self-interest and more by conformation to the norms of fairness (Jung et al., 2014). Hence, considerable differences also exist in their sensitivity to psychological distance, such that PIF (vs. DR) is more sensitive to changes in social distance between the giver and the receiver. As explanation, direct reciprocity, by definition, occurs between individuals who interact repeatedly and hence the psychological distance between the giver and the receiver is generally low. In contrast, PIF deals with anonymous interactions between complete strangers and hence the psychological distance between the giver and the receiver is by nature very high. Even slight interactions between the receiver and the giver-such as shaking hands (Bohnet \& Frey, 1999), disclosing the name of the recipient (Charness \& Gneezy, 2008), or merely showing a photograph of the recipient (Burnham, 2003) — can shorten the social distance between the receiver and the giver in the context of PIF. However, similar actions are less likely to affect the giver-receiver social distance for DR because they are "close others" to begin with. Thus, PIF is sensitive to the contextual changes that can reduce the psychological distance between the giver and the receiver, more so than DR.

Due to such differences, we expect that construal level can provide a theoretical foundation to explain differences in PIF and DR. Specifically, compared to DR or "tit-for-tat," PIF is more susceptible to psychological distance between the receiver and the giver, as the likelihood of individuals to engage in paying forward to strangers depends upon how much trust they feel toward the recipient, what inferences they draw on being a part of a PIF chain, and how much feelings of obligation they get from not passing on a gift. In general, individuals have more trust toward close (vs. distant) others. Also, feelings of obligation and fairness are affected by whether the recipient is a close other or a distant other (Bolton, Katok, \& Zwick, 1998). Next, we develop conceptual distinctions between PIF and DR from a construal level perspective.

\subsection{PIF and DR: a construal level perspective}

Past research on construal level theory (CLT) identifies four dimensions of psychological distance that influence consumers' construal of information and their subsequent decisions: temporal, social, spatial, and hypothetical distance (Liberman, Trope, \& Wakslak, 2007). The core thesis is that increased distance enhances abstractness and level of mental construal of an event. According to Liberman et al. (2007), judgments made by individuals reflect the induced mental construal, such that psychological distance increases the weight of abstract, global aspects of the situation and reduces the weight of secondary, contextual aspects.

As discussed earlier, paying kindness forward, especially PIF, is sensitive to the influence of psychological distance. Although not being examined in the PIF context, previous research shows that making salient the social distance between the giver and the receiver does affect altruistic behavior, as individuals show a greater preference for ingroup members, due to a need 
to maintain reputation (Mifune, Hashimoto, \& Yamagishi, 2010), or due to parochial reasons that govern future expectations from the recipient (Yamagishi \& Mifune, 2016). Construal level can mitigate such sensitivity to giver-recipient social distance, especially for PIF, because activating an abstract mindset increases the reliance on general reciprocity norms and the relative neglect of context-specific considerations (Torelli \& Kaikati, 2009). Under concrete construal, however, individuals become less rigid in implementing their reciprocity norms, and base it more on the relational norms (Baron \& Leshner, 2000). Based upon the CLT framework, we identify three important factors that help advance our understanding about the difference between PIF and DR, including individual difference in individualism-collectivism orientation, charitable cause type (immediate vs. delayed impact), and donation intention-behavior consistency.

\section{Hypothesis development}

\subsection{Cultural differences in PIF and DR tendency}

Previous research shows that collectivists place a greater weightage on close relationships and hence construe events much more in the here and now or concrete fashion (McCrea, Wieber, \& Myers, 2012). In contrast, individualists are less sensitive to psychological distance and construe events in the abstract form; thereby not perceiving a clear difference between ingroup and outgroup (Yang \& Laroche, 2011). This leads us to predict that collectivists will show a marked difference between PIF and DR, because the recipient of PIF is often a stranger (an outgroup member) and the recipient of DR is usually a known person (an ingroup member). Due to their low level construal, collectivists are sensitive to such a distinction between ingroup and outgroup members. In contrast, individualists will show less discrimination between DR and PIF because their high level construal mitigates the distinction between ingroup and outgroup.

This prediction is also supported by the difference in goal orientation across the individualists and the collectivists. While the goals of the individualists are oriented toward seeking benefits, gains, and self-enhancements, the goals of the collectivists are oriented toward avoiding uncertainty, mistakes, and losses (Aaker \& Lee, 2001; Ma, Yang, \& Mourali, 2014). The difference in general proclivities to benefits and risks plays an important role in shaping individuals' propensity to engage in reciprocity behavior, because the degree of obligation to reciprocate is a function of the cost of breaking a relationship (Sierksma, Thijs, Verkuyten, \& Komter, 2014). Since the cost of breaking the relationship with a close friend is much higher than the cost of breaking the relationship with distant others, the orientation to avoiding costs in making moral decisions among collectivists is likely to drive them to further differentiate between PIF and DR. Taken together, we hypothesize:

H1a. Collectivists show a marked difference between PIF and DR, such that they have a lower tendency to engage in PIF than to engage in DR.

H1b. Individualists have similar levels of tendency to engage in PIF and DR.

3.2. PIF and DR differences in the context of donation 
Individuals high in PIF conform to the norms of fairness (Jung et al., 2014), thereby not drawing a clear distinction between close and distant others, and willing to pay kindness forward to both types of people. In contrast, individuals high in DR concern about their own benefit and costs associated with reciprocation and draw a clear distinction between close and distant others, leading to their higher levels of paying kindness back to close others (ingroup members) than to strangers (outgroup members). Due to such differences in reaction to social distance, we believe that PIF and DR have differential effects on: (1) the likelihood of donating to the causes with immediate vs. delayed impact, and (2) the degree of donation intention-behavior consistency.

\subsubsection{The likelihood of donating to the causes with immediate vs. delayed impact}

Some charitable causes have immediate outcome on human well-beings, whereas the outcome of other causes may not be obvious in a short run (Hossain \& Yang, 2014). For example, tree plantation takes a delayed time period for people to see the effects, whereas the impact of buying food for hungry children is fast and immediate. Also, the environment may enjoy the positive impact of tree plantation over a continued period of time. In contrast, the impact of helping the causes that are related to the direct welfare of human lives is likely to have a narrower timeframe (e.g., food for a day or so). Conceptually, these two types of causes differ in the nature of their outcome characteristics around immediacy, which contains two aspects: (1) how much time it takes for the impact to take place, and (2) how long the impact can last (Hossain \& Yang, 2014).

We expect PIF and DR to have differential effects on the preference for the causes with immediate (vs. delayed) impact in such a way that individuals high and low in PIF do not differ in their preference of cause type; however, those high (vs. low) in DR prefer the causes with immediate over delayed outcome. As discussed earlier, individuals high in PIF are oriented to uphold the norms of fairness, which is usually associated with higher level construal (Kim, Sung, \& Drumwright, 2018). High level construal leads individuals to value both short-term and longterm outcomes, as they tend to perceive short-term outcomes as elements of a connected whole of the long-term outcome (Hossain \& Yang, 2014). In contrast, individuals high in DR are oriented to self-interest, which is usually accompanied by lower level construal, driving them to prefer less temporal distance (or more immediate rewards) as compared to greater temporal distance (or more distant rewards; Kim et al., 2018). Thus, we hypothesize:

H2a. Individuals high (vs. low) in DR have lower preferences for the charitable causes with delayed (vs. immediate) impact.

H2b. Individuals high and low in PIF show equal preferences for the charitable causes with immediate or delayed impact.

\subsubsection{Donation intention-behavior consistency}

We further anticipate that PIF and DR have differential effects on donation intention-behavior consistency such that PIF increases donation intention-behavior consistency but DR decreases donation intention-behavior consistency. As mentioned earlier, individuals high in DR tend to construe events at a much lower construal level and engage in concrete thinking. Concrete thinking tends to induce a more myopic (vs. hyperopic) view (Kivetz \& Keinan, 2006). Myopic 
view, in turn, enhances preference for immediate indulgence and impulsive consumption (Green, Fry, \& Myerson, 1994). Due to their myopic view, when facing donation request, individuals who are concerned with self-interest tend to show high levels of donation intention, as an approach to alleviate immediate negative feelings. However, when behavior happens later, donation intention and behavior become two discrete decisions for them, leading less intentionbehavior consistency. In contrast, concern for conformation to the norms of fairness is often associated with farsightedness. Pre-commitment is more effective for those who are likely to think abstractedly (Zhao \& Xie, 2011). This also explains why those focusing on others are less likely to engage in impulsive consumption (Zhang \& Shrum, 2009). For them, pre-commitment and behavior are two parts of the same decision.

H3. PIF tendency is positively related to donation intention-behavior consistency, whereas DR tendency is negatively related to it.

\section{Study 1: pay-it-forward tendency scale}

The objective of this study is to develop a measure of Pay-it-forward Tendency. In the present research, pay-it-forward tendency is conceptualized as a unidimensional construct that focuses on individuals' inclination to "pass-it-over the kind acts." Following established scale development procedures (Churchill, 1979), we constructed the instrument through literature review, focus groups, and experts.

\subsection{Scale development}

A new scale was developed for PIF tendency. Items for the scale were generated following a combination of inductive and deductive approaches. First, a pool of items was gathered from the literature on reciprocity, especially positive direct reciprocity (Perugini et al., 2003), and these items were adapted to the conceptual domain of PIF. Then, in order to achieve a richer spectrum of items, we discussed the measures with five $\mathrm{Ph}$.D. students, 10 undergraduate students, and three researchers. Duplicate items were then eliminated, leaving 12 items that were intended to reflect the domain of interest (see Appendix for the exact wording of the items).

In order to ensure an adequate level of content and face validity, three researchers in marketing and three researchers from social psychology at major research universities were asked to act as expert judges to evaluate the remaining items with regard to how well they reflected the full content of the PIF tendency construct (assessment of content validity) and how well they reflected the intended construct and not some other constructs (assessment of face validity). In addition, the experts were asked to point out ambiguously worded items and redundant items. The experts were asked to score the items on a scale where 1 is "not at all representative," 2 is "somewhat representative," and 3 is "completely representative" (Zaichkowsky, 1985).

Following previous research (Hardesty \& Bearden, 2004), we followed the sum-score rule to decide which items to eliminate. Specifically, we added up the scores from the expert judges for each item and eliminated the items with total scores $<15$. A total score of 15 represents the situation where no expert judges score the item as "not at all representative" and at least half of the experts judged the item to be "completely representative." As a result of the expert judges' evaluations, five items were eliminated, leaving seven. 


\subsection{Sample and procedures}

A sample of 504 Americans from Mechanical Turk (50.2\% male; $\left.M_{\text {age }}=38.81, \mathrm{SD}=14.07\right)$ participated in this study in exchange for a small amount of monetary incentive. Participants rated their level of agreement on the remaining seven items of PIF tendency. To show that this scale is different from DR tendency, we also assessed participants' DR tendency using the items developed by Perugini et al. (2003). The sample was randomly split into two equal groups, following established scale development procedures (Noar, 2003). Exploratory factor analysis (EFA) was carried out on one half of the sample to reduce the pool of items and confirmatory factor analyses (CFA) were performed on the other half in order to assess unidimensionality of the Pay-it-Forward Tendency Scale.

\subsection{Results}

First, an EFA was carried out on one half of the sample. One factor emerged from the data as expected. The loadings of the factor were all greater than the critical threshold 0.50 (Hair, Anderson, Tatham, \& Black, 1998). In addition, each item was evaluated to verify whether deleting it would significantly change the domain of the construct. The evaluation of the item-tototal correlations resulted in the removal of one item, leaving six.

Next, the model was subjected to CFA in order to verify its unidimensionality. The data were obtained from the second half of the split sample, providing 252 responses for the CFA. The Kaiser-Meyer-Olkin measure (Kaiser, 1974) and the Bartlett test of sphericity (Bartlett, 1951) revealed that the data was appropriate for a factor analysis, with $\mathrm{KMO}=0.91$, BTS $=1358.4$, $\mathrm{df}=15, p<.001$. In order to decide how many factors to retain, we performed a Scree Test (Zwick \& Velicer, 1986) and a Parallel Analysis (Horn, 1965). The items loaded on a single factor as predicted, supporting unidimensionality (Gerbing \& Anderson, 1988).

To test whether the scale of Pay-it-Forward Tendency and the construct of Direct Reciprocity Tendency are connected but distinct factors, we performed a CFA on the measurement model that contains these two factors. Estimation displayed desirable goodness of fit statistics for our data, as indicated by $\chi^{2}(89)=230.73, \mathrm{df}=89, p=.000, \mathrm{CFI}=0.946, \mathrm{RMSEA}=0.067$. We then assessed convergent and discriminant validity of these two factors. ${ }^{3}$ Evidence of the former relates to the extent to which items correlate strongly with other items used to measure the same construct, while the latter refers to the degree to which measures of different constructs are unique from each other (Churchill, 1979). According to Fornell and Larcker (1981), convergent validity is established if the average variance extracted for each factor accounts for 0.50 or more of the total variance. The results confirmed convergent validity of these factors extracted from our data, with the average variance extracted for the factors were both above the 0.50 cut-off value. Moreover, convergent validity is demonstrated by statistically significant path coefficients (Gerbing \& Anderson, 1988). In this study, all coefficients were significant at the $p<.001$ level.

\footnotetext{
${ }^{3}$ In Studies 2 and 3, we assessed discriminant validity of these two factors in the same way as in Study 1. Results continued to show discriminant validity of these two constructs.
} 
Discriminant validity is established if the average variance extracted is larger than the squared correlation coefficients between factors (Fornell \& Larcker, 1981). Results showed that this criterion was met across this pair of factors. Furthermore, results from LaGrange Multiplier tests indicated no significant cross-loadings for measurement items with non-hypothesized constructs; thus providing additional evidence on the discriminant validity of these constructs. ${ }^{4}$

\section{Study 2: GITHUB public vs. private repository posting}

Open source software development depends on the contributions (time and effort) from software professionals. Software improvement codes are shared using forges, of which GUTHUB is the biggest software forge used by software professionals to share code improvements with others (Cosentino, Canovas Izquierdo, \& Cabot, 2017). GITHUB hosts two types of repositories to which users can post - a public repository and a private repository (Kalliamvakou, Damian, Blincoe, Singer, \& German, 2015). Posting in a public repository ensures open access, and improvements are accessible to all users, with virtually no benefit to the author who posted the code improvements. As a result, posting in a public repository involves altruistic intent, or is driven by PIF type of reciprocity. In contrast, posting to a private repository only allows those who have been granted permission by the author (e.g., colleagues belonging to the author's company) to access and download. Posts in a private repository are not anonymous, often belonging to a well-knit community helping each other improve a fragment of code so that it is mutually beneficial, or driven by DR. As evident, when talking about the public repository, a user mentioned that "The community helped me a lot, so I tried to help others" (Shah, 2006). Yet, when talking about the private repository, users shared that "Organizations use repositories that are private... and individuals make changes to software of people they know so they can help each other" (Begel, Bosch, \& Storey, 2013).

The purpose of this study was to collect data from software professionals in India and the U.S., and examine their actual behavior of posting software code improvements in private or public repositories, which reflect PIF and DR, respectively. Previous research (e.g., Yang, Floyd, and Tanner, forthcoming; Yang \& Laroche, 2011) shows that India is a collectivistic country, whereas the U.S. is an individualistic country. Although not all Indians are highly collectivistic and not all Americans are highly individualistic, a majority of Indians have a dominant collectivistic self-view, whereas a majority of Americans have a dominant individualistic orientation (Ma et al., 2014). In fact, there are three benefits of using Indian and American software developers to test our theory: (1) Code-sharing is pretty common in both countries, (2) The Indians are fluent in English, which minimizes the potential confounds caused by language differences, and (3) Compared to ordinary Indians, Indian software developers tend to be less collectivistic and thus provide a conservative test on our theory.

\subsection{Sample and procedures}

\footnotetext{
${ }^{4}$ A follow-up study was conducted using 259 Indians (59.3\% male; $\left.\mathrm{M}_{\mathrm{age}}=34.07, \mathrm{SD}=10.20\right)$ recruited from Mechanical Turk. Following Byrne's (1994) approach and introducing measurement-level constraints (i.e., configural invariance, metric invariance, factor covariance invariance, and error variance invariance), we found that the factors in our American and Indian samples had the same factor patterns, factor structure, and factor covariances. Therefore, the PIF scale is invariant across the Americans and the Indians.
} 
We commissioned the study with Qualtrics to locate software programmers in the U.S. and India. Eligible participants met with the following four criteria: (1) They are currently working as a software professional in a firm, (2) They are aware of GITHUB and have posted code in GITHUB at least once in the last year, (3) They have accessed posts from GITHUB at least once in the last year, and (4) American respondents were born and raised in the U.S., whereas Indian respondents were born and raised in India. Each respondent received \$20 for their participation in the survey, which lasted about $7 \mathrm{~min}$. A total of 99 software professionals participated in the study, with 44 from the U.S. and 55 from India.

Participants were first asked to rate on two items $(\alpha=0.85)$ measuring their historical posting behavior, with a higher score indicating their relative preference for posting in public over private repositories: (1) On average how would you classify your posts to GITHUB?, and (2) If you were to divide up the previous posts you made to GITHUB, how would you classify your posts? (1 = Only private, no public; 2 = Mostly private, occasionally public; 3 = Slightly more private than public; $4=$ Equally private and public; $5=$ Slightly more public than private; $6=$ Mostly public occasionally private; and $7=$ Only public, no private). They then provided ratings on how knowledgeable and how familiar they were of GITHUB $(1=$ Not at all; $5=$ Extremely).

Finally, participants provided ratings on the Positive Direct Reciprocity Scale (e.g., "If someone does a favor for me, I am ready to return it"; $\alpha=0.91$ ) developed by Perugini et al. (2003), and the Pay-It-Forward Scale developed in Study 1 (e.g., "When a stranger does a good deed for me, I want to pay it forward by doing a good deed for someone else"; $\alpha=0.89$ ).

\subsection{Results}

\subsubsection{PIF and DR as a function of individualism-collectivism}

Hypotheses $1 \mathrm{a}$ and $1 \mathrm{~b}$ state that (a) Collectivists have a lower tendency to engage in PIF than to engage in DR, and (b) Individualists have similar levels of tendency to engage in PIF and DR. To test this hypothesis, we performed an independent sample $t$-test, using the composite scores of PIF and DR tendency as the dependent variables. Results revealed that, consistent with $\mathrm{H}_{1 \mathrm{a}}$, the Indians had a lower level of PIF tendency $(M=4.82)$ than DR tendency $(M=5.71$; $t(98)=-8.02, p<.001)$. Also supporting $\mathrm{H}_{1 \mathrm{~b}}$, the Americans had no difference in their PIF tendency $(M=5.34)$ and DR tendency $(M=5.62 ; t(98)=-1.46, p=.15)$.

\subsubsection{Posting in public vs. private repositories as a function of individualism-collectivism}

We also conducted an independent sample $t$-test, using an average of the two-item measure of relative preference for posting in public (vs. private) repositories as the dependent variable. Results revealed that, consistent with $\mathrm{H}_{1}$ a, the Indians posted less in public than in private repositories $\left(M=3.41\right.$ vs. $\left.M_{\text {mid-point }}=4.00 ; t(54)=-2.28, p<.03\right)$. Also supporting $\mathrm{H}_{1 \mathrm{~b}}$, the Americans had no difference in their preference for posting in private or in public repositories $\left(M=4.27\right.$ vs. $\left.M_{\text {mid-point }}=4.00 ; t(43)=1.26, p=.18\right)$. 


\subsubsection{Ruling out familiarity and knowledge as alternative explanations}

To rule out familiarity and knowledge as alternative explanations, we submitted them into an independent sample $t$-test. The software professionals from the Americans $(M=4.32)$ were equally familiar with the usage of GITHUB as the Indians $(M=4.12 ; t(98)=1.42, p=.15)$. Similarly, the Americans $(M=4.24)$ were equally knowledgable about GITHUB as the Indians $(M=4.41 ; t(98)=-1.26, p=.21)$. Therefore, our findings cannot be explained by familiarity or knowledge.

\subsubsection{Mediation analysis}

Mediation analysis was conducted to test our assumption that the effect of country (independent variable) on posting to a public (vs. private) repository, which was used as a surrogate for PIF behavior on GITHUB (dependent variable), would be mediated by PIF tendency (mediator). A bootstrapping procedure with 10,000 iterations using Model 4 of Hayes' (2012) PROCESS showed that the indirect effect of country on PIF behavior via PIF tendency was positive (0.19) and significant ( $95 \%$ CI, 0.019 to 0.41 excluded zero). These results provided additional support for $\mathrm{H}_{1 \mathrm{a}}$ and $\mathrm{H}_{1 \mathrm{~b}}$. Including knowledge about and familiarity with GITHUB as covariates did not change the result pattern. Further, DR tendency was not a mediator for the relationship between country and PIF behavior since the indirect effect of country on PIF behavior via DR tendency was insignificant $(95 \% \mathrm{CI},-0.121$ to 0.051 included zero).

\subsection{Discussion}

Using both tendency measures and reciprocity behavior, Study 2 provided support for $\mathrm{H}_{1 \mathrm{a}}$ and $\mathrm{H}_{1 b}$ that collectivists have a lower tendency to engage in PIF than to engage in DR, but individualists have similar levels of tendency to engage in PIF and DR. Further, PIF tendency, but not DR tendency, mediates the cross-national differences in PIF behavior. Although this study used a real-life sample (software professionals in the U.S. and India), and measured a real-life behavior (GITHUB code posting), this behavior has not been examined and classified as PIF behavior in the literature. To ensure generalizability of our findings, we conducted another study using an established PIF versus DR behavior (see Gray et al., 2014; Study 3), across Indian and American participants, which featured a 2 (USA vs. India) $\times 2$ (PIF vs. DR) between-subjects design (see Web Appendix 1 for details). Results showed that, supporting $\mathrm{H}_{\mathrm{la}}$, fewer Indians engaged in pay-it-forward (5.7\%) than direct reciprocity $(22.9 \% ; t(94)=2.47, p<.05)$. Also supporting $\mathrm{H}_{1 \mathrm{~b}}$, Americans had no difference in engaging pay-it-forward $(21.9 \%)$ or direct reciprocity $(16.67 \% ; t(94)=0.76, p=.45)$. These results are consistent with those of Study 2.

To enhance the managerial implications of this research, the next study examines how PIF and DR differentially affects individuals' preference of charitable causes, as well as their intentionbehavior consistency.

\section{Study 3: cause type and donation intention-behavior consistency}




\subsection{Sample and procedures}

Data was collected in collaboration with a marketing research company that covered national geographies in the U.S. A representative sample of 337 American adults (45.4\% male; $M_{\text {age }}=40.47, \mathrm{SD}=14.58$; ranging from 18 to 65 ) was recruited to participate in a longitudinal study. At Time 1, participants were first asked to imagine that they plan to donate some money to charitable causes from a list of six options presented in a random order, including three humanitarian causes that have immediate impact on human lives (i.e., supporting children affected by Hurricane Sandy, food for low-income families, and helping hungry families put food on table) and three environmental causes with low levels of salience in short-term outcomes (i.e., protecting planet's coral reefs, helping congress understand energy and climate, and helping an environmental job corporation). They could choose as many causes as they want or just one. Our expectation was that participants preferring immediate impact would prefer humanitarian causes, whereas those in favor of delayed impact would prefer environmental causes (Hossain \& Yang, 2014). The percentage of the environmental causes in the choice set was derived to reflect their relative preference for the causes with a delayed (vs. immediate) impact.

The stimuli of these donation causes were pretested among a sample of 50 Mechanical Turk workers $\left(60 \%\right.$ female; $\left.M_{\text {age }}=33.96, \mathrm{SD}=13.28\right)$ in the U.S., regarding immediacy of impact. Participants were asked to rate the salience of short-term outcomes of donating to these causes ("immediate/delayed"; reverse-coded). Consistent with our assumptions, participants rated the outcome of the causes related to direct welfare for human beings as more salient in immediacy than the outcome of causes related to direct welfare to the environment $\left(M_{\text {humanitarian }}=5.24\right.$ vs. $\left.M_{\text {environmental }}=3.36 ; t(49)=9.73, p<.001\right)$.

Right after selecting the causes, participants were presented with news from CNN: "On April 25, 2015 a major earthquake hit Nepal and on May 12, 2015, a second earthquake hit Nepal. According to CNN, the earthquake victims urgently need help, especially in the next 30 days. How likely are you to donate to the victims in Nepal in the next 30 days?" (1 = Not Likely At All; $7=$ Very Likely). Those who did not click "not likely at all" answered a follow-up question: "If you decide to donate, how much (in \$) do you intend to donate to the earthquake victims in the next 30 days? (If you decide not to donate, please indicate ' 0 ')" At the time of the study, Nepal was just hit by the second earthquake. Afterwards, participants rated their levels of direct reciprocity $(\alpha=0.92)$ and pay-it-forward $(\alpha=0.98)$ using the same measures as in Study 2.

The participants who completed Time 1 questionnaire were invited to fill out a short survey 30 days later at Time 2, in which they were asked to report their actual donation in the past 30 days to the victims in Nepal earthquake. One hundred and seventeen participants completed the short survey in Time 2. No significant differences were found between the participants who responded to the Time 2 survey and those who did not, in terms of age, gender, donation rate, and donation amount (all $p$ 's $>.05$ ).

\subsection{Results}

$\mathrm{H}_{2 \mathrm{a}}$ and $\mathrm{H}_{2 \mathrm{~b}}$ specify that (a) individuals high (vs. low) in DR have lower preferences for the charitable causes with delayed (vs. immediate) impact, and $(b)$ individuals high and low in PIF 
show equal preferences for the charitable causes with immediate or delayed impact. Given that PIF and DR tendencies were continuous measures, $\mathrm{H}_{2 \mathrm{a}}$ and $\mathrm{H}_{2 \mathrm{~b}}$ would be supported if DR tendency, but not PIF tendency, is negatively related to preference for the causes with delayed (vs. immediate) impact. Consistent with $\mathrm{H}_{2 \mathrm{a}}$ and $\mathrm{H}_{2} \mathrm{~b}$, a regression analysis with the percentage of environmental causes as the dependent variable and DR and PIF as independent variables revealed a significant effect of DR tendency $(\beta=-0.159, t(336)=2.52, p<.05)$, but no effects of PIF tendency $(p>.15)$.

H3 posits that PIF tendency is positively related to donation intention-behavior consistency, whereas DR tendency is negatively related to it. To test this hypothesis, we derived IntentionBehavior Consistency in two ways: (1) action consistency $(0=$ promised to donate but did not give; $1=$ promised to donate and gave $)$, and (2) amount consistency $(0=$ lower than the amount indicated in T1; 1 = equal to or more than the amount indicated in T1). A regression analysis with action consistency as the dependent variable and PIF tendency and DR tendency as independent variables showed a positive effect of PIF tendency $(\beta=0.249, t(116)=2.20$, $p<.05)$, and a negative effect of DR tendency $(\beta=-0.491, t(116)=-4.39, p<.001)$. Similar analysis using amount consistency as the dependent variable revealed a marginally significant positive effect of PIF tendency $(\beta=0.188, t(116)=1.67, p=.10)$, and a negative effect of DR tendency $(\beta=-0.436, t(116)=-3.83, p<.001)$. Taken together, these results supported H3.

\section{Discussion}

This research has several key findings: First, it develops a Pay-It-Forward Tendency scale. Second, it conceptualizes the differences between PIF and DR tendency from a construal level perspective, and suggests that the difference between DR and PIF tendency is likely to be much higher among collectivists than among individualists. Further, individual differences in PIF and DR tendency have differential effects on downstream variables, such as preference of charitable causes and donation intention-behavior consistency. While people high (vs. low) in DR have lower preferences for the charitable causes with delayed (vs. immediate) impact, those high and low in PIF show equal preferences for the charitable causes with immediate or delayed impact. Besides, PIF tendency is positively related to donation intention-behavior consistency, whereas DR tendency is negatively related to it.

\subsection{Theoretical contributions}

The findings in this research have several theoretical contributions. First, the study contributes to the reciprocity literature through the development and validation of the construct of "pay-itforward tendency". Previous research in this area has investigated the antecedents of PIF (Barta et al., 2011; Rankin \& Taborsky, 2009), but there is no chronic measure to reflect the degree of PIF tendency. The PIF tendency scale not only allows researchers to identify those who are more likely to engage in PIF behavior, but also advances our understanding about qualitative differences between PIF and DR. This is especially important, as PIF and DR are wellacknowledged as being prosocial (Grant \& Dutton, 2012). However, thus far, no research has provided theoretical reasons on how they differ and the implications of these differences. We are among the first to focus on that. 
Second, this study also identifies cultural differences in PIF and DR. This is an important investigation, as both PIF and DR involve reciprocating kindness to an individual. However, they differ not just in how much an individual is likely to reciprocate under each of the conditions, but also in what factors drive reciprocation, and its impact on society. Different from DR that usually involves two to three people, PIF helps spread generosity beyond the two or three people and form a part of the generosity chain, and thus allows altruism to evolve and percolate through society (Nowak \& Roch, 2007). Previous research suggests that reciprocity varies by culture (Buchan et al., 2002); however, it is unclear about how and why reciprocity differs in different countries. Having a valid measure of PIF tendency opens a new research venue and allows future scholars to understand more about the phenomenon.

Third, the conceptualization on the difference between PIF and DR also contributes to the donation literature. As per our theorizing, differences in PIF and DR are manifested into downstream moral judgements, including individuals' relative preference for the type of charity one chooses to donate to. The predictions are not straightforward as one would expect. On one hand, both PIF and DR tendencies enhance donation likelihood. On the other hand, DR tendency, but not PIF tendency, leads individuals to prefer causes with immediate (vs. delayed) impact. In addition, PIF tendency positively, but DR tendency negatively, affects donation intentionbehavior consistency. Our research provides theoretical explanations about the psychological processes underlying the differentiating effects of PIF tendency and DR tendency. The key is in individuals' sensitivity to the psychological distance between the giver and the receiver. DR is usually driven by self-interest due to concrete thinking (Boster, Fediuk, \& Kotowski, 2001), whereas PIF is driven by conformation to the norms of fairness due to abstract thinking. This theorizing is very critical to expand the research stream, as future researchers can identity meaningful theoretical moderators to enhance desirable reciprocity behavior.

\subsection{Managerial implications}

Apart from its theoretical contributions, our research also brings important insights to managers, especially those that deal with open source software. As in Study 2, our findings suggest that contribution to public repositories that help both known and unknown professionals is likely lower among collectivists. This is because individuals in these countries (e.g., India) have a decreased tendency to PIF as compared to individuals in individualistic countries (e.g., the U.S.). This probably explains why the mutually collaborative model of Silicon Valley, with respect to PIF chains of open source development driving up innovation, is difficult to be replicated in India, despite the fact that India has many talented software engineers. Our findings indicate the importance for firms in collectivistic countries to use contextual ways to increase PIF tendency. One possibility is to use ad appeals to show how much immediate impact they can exert on the beneficiaries. As shown in Study 3, collectivists are prone to engage in pro-social behaviors that can allow them to see the impact of their deeds right away.

Also, marketers may capitalize on situationally activated conformation to the norms of fairness to enhance individuals' paying forward behavior in both traditional and virtual settings. The marketplace abounds in situational contingencies that impact the salience of the norms of fairness. For example, alerting product purchasers about how much they benefited from others' online reviews may enhance their likelihood to share their own evaluations on the product, which 
can potentially benefit future buyers. In a similar way, the norms of fairness can be activated in the world of software development. Providing a webpage or a wall that recognizes the individuals that post in public repositories and the country-of-origin of the posts may make salient the contributions leading to greater participation among collectivists in public repositories.

Also, in the normal donation setting, we can make potential donors aware of what people may get affected by their inaction, so that the norms of fairness can be made salient. One approach is to situationally activate individuals' perspective taking, since when other-benefit of a cause is made salient, social desirability of helping gets activated and self-serving motivations are subdued (Fisher, Vandenbosch, \& Antia, 2008). Another approach is to combine PIF and DR activities with donation events. This strategy is especially useful when the decision context is prone to inducing a particular type of reciprocity. For example, marketers may find it effective to ask for online donations in a public repository at GITHUB, where PIF tendency is likely to be enhanced. In that case, the outcome of the donation cause can be framed as having either humanitarian or environmental benefits. However, in a private repository at GITHUB, where DR tendency is likely to be salient, it is desirable for marketers to frame the cause as having humanitarian benefits, because DR leads individuals to be in favor of causes with immediate impact.

In Web Appendix 2, we present a preliminary analysis of secondary data of a PIF message shared by Facebook users (815,000 times) across 10 different countries. Matching these data with the national level individualism/collectivism score, we find that individualism was positively related to PIF share $(b=965.3, t(8)=2.26, p<.05)$, even after controlling for the positive effect of number of Facebook users $(b=2118.2, t(8)=20.70, p<.01)$. These results provide strong evidence on the application of our theory to the high-tech context beyond open source software development.

\subsection{Limitations and future research directions}

Although this research uses various types of data (cross-sectional, longitudinal, behavioral, and secondary) to provide strong support for the theoretical differences between PIF and DR, it has several limitations. A first limitation is that we did not control for the effects of individual level collectivism/individualism in cross-national studies (Study 2 and Web Appendix 1), and as a result, we do not really know whether the country differences are driven by collectivism/individualism or other national level factors. Related to above, it is also fruitful for future researchers to situationally activate individuals' collectivism/individualism (see Ma et al., 2014 for the prime procedures and stimuli) and examine our hypothesized effects. Another limitation is that the present research focuses on a one-time donation, not a series of sequential donations. It is possible that PIF tendency may drive individuals to be persistent in the depth of support (e.g., supporting only one cause with a large donation amount), whereas DR tendency may lead to favoring the breadth of support (e.g., supporting a variety of causes with a small donation amount for each). A third limitation is that the present research focuses mainly on monetary donations. Donation currency (e.g., time and money) may interact with individuals' reciprocity tendency to affect donation intention. Previous research (Liu \& Aaker, 2008) shows that thinking about donating time puts people into an emotional mindset and increases their 
donation, whereas thinking about donating money leads them to be cognitive and reduces their intent to donate. Therefore, it is fruitful for future researchers to examine how donation currency may set up a boundary condition for our findings. Finally, while we look at attitude-behavior consistency, recent research (Schwabe, Dose, \& Walsh, 2018) has started to look at factors affecting moral consistency (i.e., the notion that consumers repeat their prior moral and immoral decisions). A logical extension for our research is to examine the effects of PIF proclivity on moral consistency and to identify potential contingencies of such effects.

\section{Appendix A. Pay-it-forward tendency}

1. If a person does me a favor and I don't know who this person is, I like to "pay it forward" by doing a favor for another stranger.

2. If someone does something for me and I don't know who this person is, I want to return the favor to another person.

3. If I am the recipient of a random act of kindness, I want to "give back" by performing an act of kindness for someone else.

4. When a stranger does a good deed for me, I want to pay it forward by doing a good deed for someone else.

5. When someone comes to my aid, I feel inspired to help others by performing a random act of kindness to someone else.

6. When someone does something nice for me, I am ready to do nice things for other people.

7. If a random stranger helped me, I would feel like I needed to help someone else to keep the chain of kindness going.*

8. If a stranger buys me a coffee, I want to reciprocate by buying a coffee for someone behind me.*

9. When someone at random does something nice for me, I feel like I owe the world a debt of kindness that I have to pay back.*

10. If I receive a stranger's act toward me, my behavior toward other people would not be affected. (R)*

11. If someone does something nice for me, I may not necessarily pass along that kindness to someone else. $(\mathrm{R})^{*}$

12. Even if a stranger did something nice for me, I don't feel obligated to do something nice for anyone else. $(\mathrm{R})^{*}$

\section{Appendix B. Web Appendix}

Web Appendix of this article can be found online at https://doi.org/10.1016/j.jbusres.2018.11.050.

\section{References}

Aaker, J. L., \& Lee, A. Y. (2001). 'I' seek pleasures and 'we' avoid pains: The role of selfregulatory goals in information processing and persuasion. Journal of Consumer Research, 28(June), 33-49. 
Bahr, G., \& Requate, T. (2014). Reciprocity and giving in a consecutive three-person dictator game with social interaction. German Economic Review, 15(3), 374-392.

Balliet, D., Wu, J., \& De Dreu, C. K. W. (2014). Ingroup favoritism in cooperation: A metaanalysis. Psychological Bulletin, 140(6), 1556-1581.

Baron, J., \& Leshner, S. (2000). How serious are expressions of protected values? Journal of Experimental Psychology: Applied. 6(3), 183-194.

Barta, Z., McNamara, J. M., Huszár, D. B., \& Taborsky, M. (2011). Cooperation among nonelatives evolves by state-dependent generalized reciprocity. Proceedings. Biological Sciences/The Royal Society, 278(1707), 843-848.

Bartlett, M. S. (1951). A further note on the tests of significance in factor analysis. British Journal of Statistical Psychology, 4(January), 1-2.

Begel, A., Bosch, J., \& Storey, M. A. (2013). Social networking meets software development: Perspectives from git hub, MSDN, stack exchange, and top coder. IEEE Software, 30(1), $52-66$.

Bohnet, I., \& Frey, B. (1999). The sound of silence in prisoner's dilemma and dictator games. Journal of Economic Behavior and Organization, 38(1), 43-58.

Bolton, G. E., Katok, E., \& Zwick, R. (1998). Dictator game giving: Rules of fairness versus acts of kindness. International Journal of Game Theory, 27, 269-299.

Boster, F. J., Fediuk, T. A., \& Kotowski, M. R. (2001). The effectiveness of an altruistic appeal in the presence and absence of favors. Communication Monographs, 68(December), 340346.

Buchan, N. R., Croson, R. T.a., \& Dawes, R. M. (2002). Swift neighbors and persistent strangers: A cross-cultural investigation of trust and reciprocity in social exchange. American Journal of Sociology, 108(1), 168-206.

Burnham, T. C. (2003). Engineering altruism: A theoretical and experimental investigation of anonymity and gift giving. Journal of Economic Behavior and Organization, 50, 133144.

Byrne, B. (1994). Structural equation modeling with EQS. Sage Publications.

Charness, G., \& Gneezy, U. (2008). What's in a name? Anonymity and social distance in dictator and ultimatum games. Journal of Economic Behavior and Organization, 68(1), 29-35.

Churchill, G. A. (1979). A paradigm for developing better measures of marketing constructs. Journal of Marketing Research, 16(1), 64-73.

Cialdini, R. B., \& Goldstein, N. J. (2004). Social influence: Compliance and conformity. Annual Review of Psychology, 55, 591-621.

Cosentino, V., Canovas Izquierdo, J. L., \& Cabot, J. (2017). A systematic mapping study of software development with GitHub. IEEE Access, 5, 7173-7192. 
Diekmann, A. (2004). The power of reciprocity: Fairness, reciprocity, and stakes in variants of the dictator game. The Journal of Conflict Resolution, 48(4), 487-505.

Eyal, T., Liberman, N., \& Trope, Y. (2008). Judging near and distant virtue and vice. Journal of Experimental Social Psychology, 44(4), 1204-1209.

Fisher, R. J., Vandenbosch, M., \& Antia, K. D. (2008). An empathy-helping perspective on consumers' responses to fund-raising appeals. Journal of Consumer Research, 35(3), 519531.

Fornell, C., \& Larcker, D. F. (1981). Evaluating structural equation models with unobservable variables and measurement error. Journal of Marketing Research, 18(1), 39-50.

Fujita, K., Eyal, T., Chaiken, S., Trope, Y., \& Liberman, N. (2008). Influencing attitudes toward near and distant objects. Journal of Experimental Social Psychology, 44(3), 562-572.

Gerbing, D. W., \& Anderson, J. C. (1988). An updated paradigm for scale development incorporating unidimensionality and its assessment. Journal of Marketing Research, 25(2), 186-192.

Giving USA (2013). The annual report on philanthropy. Giving USA Foundation ${ }^{\mathrm{TM}}$.

Gouldner, A. W. (1960). The norm of reciprocity: A preliminary statement. American Sociological Review, 25(2), 161-178.

Grant, a., \& Dutton, J. (2012). Beneficiary or benefactor: Are people more prosocial when they reflect on receiving or giving? Psychological Science, 23(9), 1033-1039.

Gray, K., Ward, A. F., \& Norton, M. I. (2014). Paying it forward: Generalized reciprocity and the limits of generosity. Journal of Experimental Psychology. General, 143(1), 247-254.

Green, L., Fry, A., \& Myerson, J. (1994). Discounting of delayed rewards: A life span comparison. Psychological Science, 5, 33-36.

Hair, J., Anderson, R., Tatham, R., \& Black, W. (1998). Multivariate data analysis (5 ed.). New Jersey: Prentice Hall.

Hardesty, D. M., \& Bearden, W. O. (2004). The use of expert judges in scale development: Implications for improving face validity of measures of unobservable constructs. Journal of Business Research, 57(2), 98-107.

Hayes, A. F. (2012). Process: A versatile computational tool for observed variable mediation, moderation, and conditional process modeling (white paper). Retrieved from http://www.afhayes.com/public/process2012.pdf.

Horn, J. L. (1965). A rationale and test for the number of factors in factor analysis. Psychometrika, 30(2), 179-185.

Hossain, M., \& Yang, Z. (2014). In J. Cotte, \& S. Wood (Vol. Eds.), NA - Advances in Consumer Research: . Vol. 42. Effect of thinking style on donation: Moderating role of cause type (pp. 512-513). Duluth, MN: Association for Consumer Research. 
Jung, M. H., Nelson, L. D., Gneezy, A., \& Gneezy, U. (2014). Paying more when paying for others. Journal of Personality and Social Psychology, 107(3), 414-431.

Kaiser, H. F. (1974). An index of factorial simplicity. Psychometrica, 39(March), 31-36.

Kalliamvakou, E., Damian, D., Blincoe, K., Singer, L., \& German, D. M. (2015). Open sourcestyle collaborative development practices in commercial projects using GitHub. Proceedings - International Conference on Software Engineering, 1, 574-585.

Kang, A. R., Kim, H., Woo, J., Park, J., \& Kim, H. K. (2015). Altruism in games: Helping others help themselves. Annual workshop on network and systems support for games (2015January).

Kelln, B. R. C., \& Ellard, J. H. (1999). An equity theory analysis of the impact of forgiveness and retribution on transgressor compliance. Personality and Social Psychology Bulletin, 25(7), 864-872.

Kim, D. H., Sung, Y., \& Drumwright, M. (2018). 'Where I come from' determines, 'how I construe my future': The fit effect of culture, temporal distance, and construal level. International Journal of Advertising, 37(2), 270-288.

Kivetz, R., \& Keinan, A. (2006). Repenting hyperopia: An analysis of self-control regrets. Journal of Consumer Research, 33(2), 273-282.

Lee, A. Y., Aaker, J. L., \& Gardner, W. L. (2000). The pleasures and pains of distinct selfconstruals: The role of interdependence in regulatory focus. Journal of Personality and Social Psychology, 78(6), 1122-1134.

Liberman, N., Trope, Y., \& Wakslak, C. (2007). Construal level theory and consumer behavior. Journal of Consumer Psychology, 17(2), 113-117.

Liu, W., \& Aaker, J. (2008). The happiness of giving: The time-ask effect. Journal of Consumer Research, 35(3), 543-557.

Ma, Z., Yang, Z., \& Mourali, M. (2014). Consumer adoption of new products: Independent versus interdependent self-perspectives. Journal of Marketing, 78(2), 101-117.

McCrea, S. M., Wieber, F., \& Myers, A. L. (2012). Construal level mind-sets moderate self- and social stereotyping. Journal of Personality and Social Psychology, 102(1), 51-68.

Mifune, N., Hashimoto, H., \& Yamagishi, T. (2010). Altruism toward in-group members as a reputation mechanism. Evolution and Human Behavior, 31(2), 109-117.

Noar, S. M. (2003). The role of structural equation modeling in scale development. Structural Equation Modeling, 10(4), 622-647.

Nowak, M. A., \& Roch, S. (2007). Upstream reciprocity and the evolution of gratitude. Proceedings of the Royal Society B-Biological Sciences, 274(1610), 605-610.

Perugini, M., Gallucci, M., Presaghi, F., \& Ercolani, A. P. (2003). The personal norm of reciprocity. European Journal of Personality, 17(4), 251-283. 
Rankin, D. J., \& Taborsky, M. (2009). Assortment and the evolution of generalized reciprocity. Evolution, 63(7), 1913-1922.

Schwabe, M., Dose, D. B., \& Walsh, G. (2018). Every saint has a past, and every sinner has a future: Influences of regulatory focus on consumers' moral self-regulation. Journal of Consumer Psychology, 28(2), 234-252.

Shah, S. K. (2006). Motivation, governance, and the viability of hybrid forms in open source software motivation, governance, and the viability of hybrid forms in open source software development. Management Science, 52(7), 1000-1014.

Sierksma, J., Thijs, J., Verkuyten, M., \& Komter, A. (2014). Children's reasoning about the refusal to help: The role of need, costs, and social perspective taking. Child Development, 85(3), 1134-1149.

Suri, S., \& Watts, D. J. (2011). Cooperation and contagion in web-based, networked public goods experiments. PLoS One, 6(3), e16836.

Taylor, L. C. (2012). Tim Hortons customers pay it forward 228 times in Winnipeg. Toronto Star. Dec. 31, 2012. Retrieved from https://www.thestar.com/news/canada/2012/12/31/tim hortons_customers pay it forwar d_228 times in winnipeg.html.

Torelli, C. J., \& Kaikati, A. M. (2009). Values as predictors of judgments and behaviors: The role of abstract and concrete mindsets. Journal of Personality and Social Psychology, 96(1), 231-247.

Tsvetkova, M., \& Macy, M. W. (2014). The social contagion of generosity. PLoS One, 9(2), e87275.

Whiteley, P. F. (2000). Economic growth and social capital. Political Studies, 48(3), 443-466.

Yamagishi, T., \& Mifune, N. (2016). Parochial altruism: Does it explain modern human group psychology? Current Opinion in Psychology, 7, 39-43.

Yang, Z. (2008). The parent-self-peer model. Saarbrücken, Germany: VDM Verlag Publishing Company.

Yang, Z., Floyd, K., \& Tanner, J. F., Jr. (2018). Effects of antismoking messages from media on adolescent smoking: The roles of family, school, and culture. Journal of Business Research (in press).

Yang, Z., \& Laroche, M. (2011). Parental responsiveness and adolescent susceptibility to peer influence: A cross-cultural investigation. Journal of Business Research, 64, 979-987.

Zaichkowsky, J. L. (1985). Measuring the involvement construct. Journal of Consumer Research, 12(3), 341-352.

Zhang, Y., \& Shrum, L. J. (2009). The influence of self-construal on impulsive consumption. Journal of Consumer Research, 35(5), 838-850.

Zhao, M., \& Xie, J. (2011). Effects of social and temporal distance on consumers' responses to peer recommendations. Journal of Marketing Research, XLVIII, 486-496. 
Zwick, W. R., \& Velicer, W. F. (1986). Comparison of 5 rules for determining the number of factors to retain. Psychological Bulletin, 99(3), 432-442. 